\title{
Treatment of Candida septicaemia in a severely scalded child with amphotericin B
}

\author{
A. N. WILSON \\ M.B., B.S., F.R.C.S.(Edin.), D.Obst., R.C.O.G. \\ Registrar in Plastic Surgery, North Staffordshire Royal Infirmary*
}

IN THE 0-15 age group, the most common fungal pathogen causing septicaemia is Candida; the most common variety isolated from such cases is Candida albicans. Reports of Candida septicaemia are uncommon but a review of the literature by Hurley in 1964 revealed sixteen cases, of which six recovered. Further review of the literature by the writer revealed ten further cases; eight reported by Dennis, Miller $\&$ Peterson (1964) and two by Andriole et al. (1962), the latter being Candida endocarditis with positive blood cultures for Candida.

Other forms of deep mycosis which may precede or succeed septicaemia include massive gastro-intestinal tract infection, endocarditis (review article by Andriole et al., 1962), urinary tract infection (Lehner, 1964) and involvement of the central nervous system (De Vita et al., 1966).

From the increasing number of reports in the literature of pathogenic infection with Candida, it seems that the predisposing factors enumerated by Winner \& Hurley (p58) should be extended to include catheters in blood vessels and body cavities in the debilitated patient. As evidence it is reasonable to quote: Candida endocarditis following open heart surgery (Newsom, Lee \& Rees, 1967); candidiasis complicating renal transplantation and immunosuppressive therapy (Rifkind et al., 1967); Candida septicaemia following dialysis in the treatment of hypotensive renal failure (Goldman, Eckerling \& Bassatt, 1967); Candida peritonitis following repeated peritoneal dialyses (Hurwich, 1966). The case to be described embraces almost all the known predisposing factors leading to generalized candidiasis.

\section{Case report}

The patient, S.M., aged 2, was admitted having suffered severe scalds after falling into a bath of nearboiling water. The burned area was estimated at $80 \%$; however, reassessment 2 days later using Lund \& Browder (1944) charts showed the area to be $70 \%$, some $30 \%$ appearing to be full thickness loss.

Treatment of the burned surfaces was by exposure and the local application of $10 \%$ icthamol in

*Present address: Registrar in Orthopaedic Surgery, New Cross Hospital, Wolverhampton, Staffordshire. glycerine (Grocott, 1962). Control of his circulatory state was by inferior caval catheter and central venous pressure monitor; the caval infusion was covered with heparin and methicillin. A complete fluid and electrolyte balance was instituted; blood acid/base state was monitored daily initially. Nutrition in the early stages was administered intravenously.

Day 8: Generalized oedema present. General condition satisfactory. Burned surfaces sterile.

Day 11: The caval catheter became blocked due to clotting of refluxed blood following trouble with the CVP monitor. Burned surfaces bacteriologically sterile but a few colonies of yeasts were noted on the culture plates. Caval catheter replaced under general anaesthetic.

Day 12: The child was greatly distressed and had the clinical signs of collapse of the right lung, confirmed on chest X-ray. Bronchoscopy was carried out and frothy oedema fluid was sucked out of the accessible branches of the right bronchus and the lung re-inflated. A nasal endotracheal tube was left in situ to facilitate bronchial toilet. Melaena first appeared at this time, but culture of the faeces yielded no Candida; total white blood cell count was 15,000 with a marked 'left shift'.

Day 13: Nasal endotracheal tube became obstructed with crusted bronchial secretion and was removed. The condition of the child was near to moribund with sufficient respiratory distress to warrant tracheostomy, digitalization (pulse rate 150-180 with a steady rise in CVP to $25 \mathrm{~cm} \mathrm{H}_{2} \mathrm{O}$ ), intravenous hydrocortisone (marked broncho-spasm unrelieved by aminophylline) and an oxygen tent.

Day 14: An endobronchial swab showed Strep. faecalis and 'yeast'; ampicillin was added to the methicillin in the drip to broaden the spectrum to include Strep. faecalis.

Day 15: The child looked frankly septicaemic, with sunken eyes, cold grey skin and obvious petechiae. Blood culture at this time yielded a growth, identified as Candida albicans.

Day 18: A blood film showed a total white count of $24,600(80 \%$ polys.) with multiple myelocytes and normoblasts. The whole slide was covered with free 
and phagocytosed mycelia. Heavy growths of Candida albicans were obtained from the faeces and swabs from the burned surfaces. Treatment was instituted urgently with amphotericin B intravenously, by lozenge and by tablet.

Day 20: Melaena had disappeared and culture of the faeces yielded no Candida albicans. The total white blood cell count reached its peak at 36,700 with only occasional myelocytes and normoblasts. Although the mycelia visible on the blood film disappeared after 3 days of treatment, the blood cultures still yielded Candida albicans. Blood cultures were taken twice a week and a culture which yielded no Candida after 3 days incubation was considered to be negative.

Day 23: Multiple large petechiae over extensor surfaces of the limbs heralded the onset of thrombocytopenia, the platelet count being $12,000 / \mathrm{mm}^{3}$; this gradually rose to more normal levels without specific therapy.

Day 55: Blood culture had yielded no Candida for 10 days when the child again appeared septicaemic; blood culture now yielded a heavy growth of Gramnegative anaerobic bacilli later shown to be bacteroides, sensitive to tetracycline. Blood culture 10 days later, after treatment with tetracycline, was sterile.

The caval catheter was eventually removed after being in situ for 10 weeks when it was discovered to be incomplete; however, there seemed to be no illeffects so thoracotomy was deferred until the child's general condition had improved. This, however, was not to be and the child died five-and-a-half months after admission from heart failure due to thrombus in his right atrium and the effects of multiple staphylococcal abscesses, the main one being in his pelvis and around his right hip joint under the site of entry of the caval catheter. During the 7 weeks of treatment with amphotericin B, there was no evidence of endocardial or central nervous system involvement with Candida; the urine remained normal on microscopy and sterile on culture.

\section{Discussion}

Source: The child's mouth was noted to contain white debris soon after admission but this was not deemed significant.

Spread: Thought to be from the mouth to the rest of the gastro-intestinal and the burned surfaces. Initially, the burned surfaces were sterile but these were soon colonized by Candida. Culture of the faeces yielded a heavy growth of Candida 2 days before the septicaemia developed. Blood stream spread was probably by two routes, namely directly down the caval catheter from the nearby contaminated burned surfaces and by direct spread from the massively infected gut (Winner \& Hurley, 1964, p. 130).

Diagnosis: By the blood culture yielding Candida, confirmed as a fulminating septicaemia by the peripheral blood film being covered with free and phagocytosed mycelia in the presence of a markedly raised white blood cell count associated with a marked 'left shift' with many myelocytes and normoblasts.

Treatment: The start of treatment was delayed for 3 days after the blood culture first yielded Candida for the following reasons: 1 . the initial culture may have been contaminated; 2 . fungaemia in infants may be a transient phenomenon (Vince, 1959; Winner \& Hurley, 1964, p. 150); 3. owing to the toxicity of amphotericin B, it was thought that definite confirmation of the diagnosis was obligatory.

Amphotericin B: A polyene antibiotic, active against fungi but not bacteria, whose toxicity is not such as to preclude its use when administered parenterally. It is thought to act on the plasma membranes of fungi at levels insufficient to damage ordinary cells. It is amphoteric and exists in a microcrystalline form (tablets and lotion) and a colloidal form when combined with desoxycholate (Fungisone $\mathrm{I} / \mathrm{V}$, Squibb). Dosage is $0.25 \mathrm{mg} / \mathrm{kg}$ intravenously initially, slowly rising to $1 \mathrm{mg} / \mathrm{kg}$. In this case, the drug was added to $200 \mathrm{ml}$ of $5 \%$ dextrose and administered via the caval drip over $6 \mathrm{hr}$ daily. The recommended duration of treatment is from 6 to 8 weeks, 7 weeks in this case.

Bio-assay of serum amphotericin B levels $19 \mathrm{hr}$ after administration showed a level of $0.45 \mu \mathrm{g} / \mathrm{ml}$ on a dose of $0.25 \mathrm{mg} / \mathrm{kg}$ and $1 \mu \mathrm{g} / \mathrm{ml}$ on a dose of $0.5 \mathrm{mg} / \mathrm{kg}$.

In this case, blood culture remained positive until the dose was raised to $1 \mathrm{mg} / \mathrm{kg}$ and did not become negative until the dose was raised to 1.3 $\mathrm{mg} / \mathrm{kg}$; thereafter the dose was reduced to $1 \mathrm{mg} / \mathrm{kg}$ and this was sufficient to maintain a negative blood culture.

The toxic effects of amphotericin B in this case were mainly nausea and vomiting and febrile reactions which occurred when the dose reached 0.75 $\mathrm{mg} / \mathrm{kg}$ and were characterized by intense peripheral vasodilatation, particularly of the head and neck, which produced hot, plum-coloured skin surfaces and intense thirst. No renal damage was noted, the blood urea and creatinine clearance remaining within normal limits. Anaemia was present and was corrected by packed cell transfusion during treatment. After stopping the treatment with amphotericin $\mathrm{B}$, the haemoglobin settled to a level of $45 \%$ with slight iron deficient characteristics on the blood film; reticulocyte count averaged $1 \%$. The serum iron level was low $(30 \mu \mathrm{g} \%)$ as was the serum folate $(2.5 \mu \mathrm{g} \%)$; serum $B_{12}$ was within normal limits. 
The anaemia did not respond to haematinics, which is not surprising considering the deep-seated staphylococcal abscesses present at this stage; however, it is pertinent to remember that treatment with amphotericin B is associated with a normochromicnornocytic anaemia which appears early in the course of treatment and is characterized by the absence of reticulocytosis with neither marrow hyper- nor hypo-plasia (Utz et al., 1964). In this case, the thrombocytopenia was thought to be due to the septicaemia, although it is described as a late manifestation of the general marrow depression caused by amphotericin B. Thrombocytopenia is also described as an early, idiosyncratic effect of treatment with amphotericin B.

Melaena was present in this case from the twelfth to the twentieth day and was thought initially to be due to stress ulceration (Curling's Ulcer) and subsequently due to the massive infection of the gut with Candida.

\section{Acknowledgments}

My thanks to the nursing staff of the Children's Ward, North Staffordshire Royal Infirmary, for their skill in both looking after the child and the endless collection of specimens and tabulation of results, to Mr J. Grocott of the North Staffordshire Royal Infirmary for permission to use his material and to Mr C. R. Knappett of the North Staffordshire Royal Infirmary for his endless help with the bacteriology and in the preparation of this paper.

\section{References}

Andriole, V.T., Kravetz, H.M., Roberts, W.C. \& Utz, J.P. (1962) Candida endocarditis. Clinical and pathologic studies. American Journal of Medicine, 32, 251-285.
Dennis, D., Miller, M.J. \& Peterson, C.G. (1964) Candida septicaemia. Surgery, Gynaecology and Obstetrics, 119, 520-530.

De Vita, V.T., Utz, J.P., Williams, T. \& Carbone, P.P. 1966). Candida meningitis. Archives of Internal Medicine, 117, 527-534.

Goldman, J.A., Eckerling, B. \& Bassat, M.B. (1967) Fatal candida septicaemia developing after hysterectomy and transfusion. American Journal of Obstetrics and Gynecology, 98, 885-886.

Grocotr, J. (1962) Burns: a possible simplification of treatment. British Journal of Plastic Surgery, 15, 277-285.

HuRLEY, R. (1964) Acute disseminated (septicaemic) moniliasis in adults and children. Postgraduate Medical Journal, 40, 644-651.

HuRwich, B.J. (1966) Monilial peritonitis. Archives of Internal Medicine, 117, 405-408.

LEHNER, T. (1964) Systemic candidiasis and renal involvement. Lancet, i, 1414.

Lund, C.C. \& Browder, N.C. (1944) The estimation of areas of burns. Surgery, Gynaecology and Obstetrics, 79, 352-358.

Newsom, S.W.B., Lee, W.R. \& Rees, J.R. (1967) Fatal fungal infection following open-heart surgery. British Heart Journal, 29, 457-460.

Rifkind, D., Marchioro, T.L., Schneck, S.A. \& Hill, R.B. (1967) Systemic fungal infections complicating renal transplantation and immunosuppressive therapy. American Journal of Medicine, 43, 28-38.

UTZ, J.P., BenNeTt, J.E., BrandRiss, M.W., Butler, W.T. \& HILl, G.J. (1964) Amphotericin B toxicity. Combined Clinical Staff Conference at the National Institute of Health. Annals of Internal Medicine, 61, 334-354.

VINCE, 2. (1959) The spread of candida in infants and children. Medical Journal of Australia, 46, 143-145 and 145149.

Winner, H.I. \& Hurley, R. (1964) Candida albicans, 1st Edn, Churchill, London.

\section{Pseudohyperaldosteronism induced by habitual ingestion of liquorice}

\author{
A. M. Holmes \\ B.Sc., M.B., M.R.C.P. \\ J. YounG $\dagger$ \\ Technical Officer
}

\author{
P. K. MARRotT* \\ M.B., B.S., M.R.C.P̈. \\ E. Prentice $\dagger$ \\ Junior Technical Officer
}

Division of Metabolism, Department of Medicine, The Royal Infirmary, Manchester, M13 9WL

\section{Case report}

The patient, a 63-year-old man, was well until 1962 when mild diabetes was discovered. His blood pressure then was $105 / 80 \mathrm{mmHg}$. He was initially

\footnotetext{
*Present address: Registrar, Birch Hill Hospital, Rochdale.

†Present address: M.R.C. Blood Pressure Unit, Western Infirmary, Glasgow.
} 